\title{
"Bolivia hoy: ¿Una democracia poscolonial o anticolonial? Seis estudios y una bibliografía seleccionada 1990-2016"
}

(EDITOR: JUAN CARLOS GÓMEZ LEYTON):

Una recensión desde tres miradas...

RECEPCIÓN: 15/11/2017 • ACEPTACIÓN: 15/11/2017

El día 17 de octubre de 2017, en el marco del Doctorado en Estudios Interculturales de la Universidad Católica de Temuco (DEI), se presentó el libro "Bolivia hoy: ¿Una democracia poscolonial o anticolonial? Seis estudios y una bibliografía seleccionada 1990-2016". La presentación del volumen estuvo a cargo de Andrés MacAdoo Espinoza, doctorante del DEI, y de los profesores del mismo Doctorado Luis Vivero y Juan Jorge Faundes, ambos doctores formados en el Programa de Doctorado en Procesos Sociales y Políticos en América Latina (PROSPAL) de la Universidad ARCIS (Santiago, Chile). Este último dato resulta relevante porque en el seno de dicho posgrado se gestaron gran parte de los trabajos que recoge la obra en comento y porque, además, las tesis doctorales de ambos profesores estudiaron, precisamente, el proceso constituyente boliviano que aborda la obra.

Dado el contexto académico descrito, las recensiones que ofrecemos a nuestros lectores, si bien se centran en el libro, en algunos pasajes refieren a la Universidad ARCIS (en particular a lo que ha significado este proyecto universitario -hoy en crisis- para la historia académica progresista de Chile), lo que quisimos mantener, respetando el sentir de los comentaristas y del propio Editor del Libro, el Dr. Juan Carlos Gómez (que participó en el lanzamiento indicado), porque, lejos de restar mérito a las recensiones, las ubica en su preciso contexto.

La obra reseñada en sí y los comentarios en referencia, dicen relación al que ha sido considerado el proceso social, político y jurídico constitucional de mayor impacto en América Latina en lo que va corrido del siglo XXI, por ello, atendida 
la convocatoria especial de este número, centrada precisamente en la participación político-democrática y los procesos constituyentes en la región latinoamericana, a continuación ofrecemos a Uds. una versión revisada de los comentarios presentados en el lanzamiento referido del libro "Bolivia hoy...". Estos tres trabajos, que en sí mismos también constituyen agudos ensayos sobre el caso boliviano plurinacional, se presentan en la forma de tres acápites que podemos decir se articulan como "una recensión desde tres miradas".

\title{
Equipo Editorial
}

\author{
ANDRÉS MACADOO ESPINOZA \\ Universidad Católica de Temuco, Chile ${ }^{1}$
}

“Bolivia hoy: ¿Una democracia poscolonial o anticolonial?” corresponde a una compilación de seis estudios en torno al notable proceso sociopolítico boliviano de las últimas décadas, para muchos autores, un caso ejemplar del laboratorio de prácticas alternativas al capitalismo, que es América Latina. A lo largo de las páginas se van discutiendo desde el análisis de las ciencias sociales críticas, las continuidades y profundas rupturas que estos acontecimientos han significado en lo social, lo político y lo cultural. El libro se estructura en seis estudios de distinta autoría y posicionamiento, más una introducción y propuesta de una bibliografía seleccionada por el Dr. Juan Carlos Gómez Leyton, en torno a la interrogante abierta sobre un hoy boliviano anti o poscolonial. Si bien estos estudios corresponden a procesos políticos siempre localizados, se distinguen dos tipos de capítulo, uno de caso que correspondería a los primeros cuatro estudios, siendo los dos últimos de análisis más general. Así, se ponen en juego distintas perspectivas y utopías en el contexto de las movilizaciones populares, campesinas e indígenas, antes, durante y después del proceso constituyente, intentando capturar los distintos argumentarios, estrategias, prácticas y luchas. De este modo se ofrece un recorrido por el devenir histórico reciente desde distintas ópticas, poniendo el foco en los múltiples actores sociales, en cuyas páginas encontramos bajo categorías como la plebe, los indígenas, los campesinos, las mujeres, los intelectuales, etcétera.

1. Psicólogo, Universidad de La Frontera; Magíster en Planificación y Gestión Territorial, Universidad Católica de Temuco; Estudiante de Doctorado en Estudios Interculturales, Universidad Católica de Temuco. 
Como punto de entrada, la Introducción revela la profundidad histórica y simbólica de estas movilizaciones en Bolivia, con un ¡basta ya! de un protagonismo central de los pueblos indígenas. A partir de la década de los 90 empieza una época de convergencias en América Latina en respuesta al dominio histórico y la dominación capitalista. Si bien, una nueva Constitución no era algo necesariamente novedoso en Bolivia, la propuesta plurinacional trastoca el cimiento fundacional del estado moderno, apareciendo como la más revolucionaria de las demandas subalternas desde 1789, que hace frente a la metropolitana visión eurocéntrica y recogiendo aportes de perspectiva local, los dominados. No solo intenta transformar las estructuras político-institucionales de la "democracia pactada" de 1982, sino que también las estructuras de poder social y político devenidas del siglo XIX. Un punto novedoso es que las Fuerzas Armadas y la clase media boliviana se desvinculan de la agenda reaccionaria de la élite tradicional. A partir de 2010 entonces se inicia la conservadora tarea de gobernar el proceso iniciado por la plebe, la revolución.

En el primer estudio, la antropóloga Elizabeth Jiménez, presenta un caso que abre y expone de modo explícito las fisuras sociales y perspectivas antagónicas, intereses en conflicto, visiones de mundo y disputa por "el proceso de cambio" post-constituyente. Este se puede apreciar en el intento estatal de construir la carretera internacional en medio del Territorio Indígena y Parque Nacional Isiboro-Sécure (TIPNIS) donde los moxeños, yuracarés y chimanes, pueblos indígenas amazónicos cazadores recolectores, de modo bien simbólico, a través de su propia existencia, eran la piedra de tope para la construcción de esta infraestructura que iba a unificar material y simbólicamente dos áreas geográficas desarticuladas, el Oriente y Occidente boliviano. Esta vía era considerada estratégica por el Gobierno, ya que aseguraría la presencia estatal y, por tanto, el aseguramiento de los derechos ciudadanos en el territorio. El estar contra la obra era estar contra las políticas sociales y la soberanía nacional. La presencia de intereses externos al boliviano, objetivado en grupos conservacionistas y ONGs extranjeras en apoyo de dichos pueblos indígenas amazónicos, atrinchera al Gobierno y desplaza el discurso neodesarrollista hacia uno antiimperialista. La represión estatal contra estas movilizaciones popularizaron aún más el rechazo a la obra y robustecieron la defensa del TIPNIS a nivel nacional y, como señala la autora, desencadena la mayor crisis política después de la nueva Constitución. Estos hechos sacan a la luz dilemas que habían estado ocultos en la etapa previa durante el proceso de movilizaciones anterior a la nueva Constitución, donde la convergencia de las llamadas luchas antineoliberales y anticoloniales, constituían de forma aparente un solo cuerpo social, pero una vez con las herramientas de cambio y control en las manos, las alternativas de las distintas colectividades aparecen como contradictorias. 
En su carácter más complejo, este no aparece como un simple desencuentro entre el Estado y pueblos indígenas, sino que también puso en confrontación distintos pueblos indígenas entre sí, para este caso, grupos amazónicos y cocaleros, en que ambos apelan al Convenio 169 de la OIT en torno a los derechos territoriales. Esta tensión entre grupos indígenas con sistemas de producción y visiones de mundo distintas es la que también aparece en el segundo y tercer estudio. Especialmente el tercero, escrito por Fabiola Escárzaga, sobre el proyecto de colonización de tierras por migrantes indígenas quechuas y aymaras en el marco de la política de reforma agraria, entre 2006 y 2009.

El juego político y cultural entre los distintos grupos indígenas no solo dinamiza sus trasfondos civilizatorios propios, sino que también sus distintas experiencias de colonización, formas de inserción al mercado, patrones de resistencia, ya sea de confrontación o huida, y la conformación de sistemas religiosos particulares en relación al territorio. En este estudio además se develan las paradojas de las nuevas reivindicaciones desde grupos indígenas por avanzar en la política de colonización de tierras, que en un contexto ideológico de descolonización, resultaba una problemática que tiene como consecuencia la estrategia gubernamental de pasar del término "colonos" al concepto "comunidades interculturales". Este escrito pone en juego el desafío de la interculturalidad entre pueblos indígenas en movimiento y repoblamiento en el departamento de Pando, al norte de Bolivia. Toda reforma agraria y transformación de la tenencia de la tierra tiene como argumentario la función económico-social de la propiedad, o el viejo lema "la tierra para quien la trabaja”, que en un lugar de enunciación aymará y quechua se asoma como movimiento descolonizador. Ahora bien, el proceso de descentralización mismo y los grados de autonomía departamental en la propuesta plurinacional, han generado convergencias entre las élites locales, en resistencia al proceso reformador de la tierra y los llamados indígenas amazónicos cooptados, en tensión con este énfasis en la productividad como legitimidad de tenencia, tensionando el paradigma aymará del Sumaq Quamaña y su puesta en práctica como representativo de todos los pueblos indígenas. La autora finalmente concluye sobre el peligro de las estrategias perniciosas en que los pueblos indígenas son las piezas del ajedrez en el tablero boliviano que confronta al Gobierno y las oligarquías locales.

Las consecuencias de este juego entre gobiernos y oligarquías aparece en el segundo estudio, de Doris Johnson, sobre el auge del Movimiento Sin Tierra boliviano (MST-bo), previo a la nueva Constitución, que desde la teoría de la estructura de oportunidades políticas, se transforma en un actor social agrario muy importante, pero que luego del momento post-constituyente, como peones del ajedrez, es 
marginalizado. Este es el más crudo de todos los escritos, debido a las muertes por enfrentamiento acontecidas en estos oscuros episodios de la historia reciente boliviana, sobresaliendo la masacre de Pananti en el municipio de Yacuiba. En este contexto y como punto crítico de la negociación del Gobierno con las élites terratenientes, se resuelve finalmente por una reforma agraria moderada, centrada en las "tierras disponibles" o zonas con menor densidad demográfica y no en la reversión de la gran propiedad agraria, funcional al neoextractivismo, objeto de lucha política del movimiento emesetista. Esta negociación es apoyada por las bases y organizaciones leales a Evo Morales, limitando el potencial de una reforma agraria más radical.

El cuarto estudio, también explora esta fundamental relación que establece el Gobierno masista con las bases y movimientos sociales, capítulo donde Andrés Leiva analiza desde una perspectiva crítica y teoría feminista, los imaginarios sociales de dos movimientos de mujeres correspondientes a la Confederación Nacional de Mujeres Campesinas Indígenas, "Bartolina Sisa” y "Mujeres Creando". En el primer caso se plantea que en esta interseccionalidad, su emancipación como mujeres queda relegada al esencialismo indígena: "las mujeres no pueden articular sujeto -como mujeres-, sino que solo pueden ser hablados por un orden social mayor que 'habla por ellas', desde antes y para siempre. Es decir, las convierte en un contenido que no tiene valor más que en su relación con este orden". Esta situación es problemática, considerando que desde teóricos y teóricas de la perspectiva feminista, esta dependencia no conduce a la liberación. El segundo caso, de "Mujeres Creando", el autor señala que al instituir una forma de percibir la sociedad en forma binaria, quedan sin posibilidad de alianzas o estrategias, permaneciendo solo en la comodidad de una aparente posición de superioridad moral. En este sentido, las primeras, las "bartolinas", son cooptadas por el aparato estatal patriarcal, las segundas, "Mujeres Creando", marginalizadas de la sociedad boliviana.

El quinto estudio, de María Teresa Zegada, aborda de modo general Bolivia y la discusión en torno a las democracias en América Latina. En este escrito se pasa por las variadas perspectivas sobre la misma crisis de la democracia y sus problemas inherentes, el muy criticado presidencialismo latinoamericano, la democracia autoritaria, y la democracia como otra de las importaciones del desde mundo europeo, otra mala copia importada por las élites. El texto cita a Held, donde se discute el ejercicio efectivo de la ciudadanía en torno a tres puntos fundamentales: que el Estado garantice su cumplimiento, la formación de una cultura ciudadana y en tercer lugar, un punto crítico para Latinoamérica, el sentido de pertenencia a una nación. Este último nudo es un desafío, dado el mosaico multiescalar de los 36 pueblos indígenas en Bolivia, que además han migrado, son móviles y donde se 
han constituido además nuevas identidades. Este es el gran dilema, si consideramos que el Estado buscaba conformar una superetnia geográfica y folclóricamente definida. Y no es solo un desafío para con pueblos indígenas, la autora, citando a Rodrick, señala que esta problemática es parte de la incompatibilidad del trilema que fuerza la relación entre Estado, Ciudadanía y Comunidad. Ahora bien, aceptar y comprender las contradicciones de la sociedad y la democracia, es propio del ejercicio democrático, en que el conflicto es la explicación misma de su existencia. La autora señala en esta sección que la nueva Constitución Política del Estado boliviano pone en relación una matriz republicana liberal plasmada en el Estado de Derecho, y la matriz indígena-campesina-comunitaria, de tipo plurinacional. Todo esto ha avanzado hasta las limitaciones de las leyes secundarias que si bien emanan de la Constitución chocan con la democracia liberal. Para Silvia Rivera Cusicanqui, esto significa una tensión constante, en donde el Estado de Derecho opaca a la matriz plurinacional.

El último estudio, presentado por Jorge Gibert explora el rol de los intelectuales y cientistas sociales a lo largo de este proceso, entre el período que va desde el 2000 al 2009. ¿Cuál es el compromiso de este tipo de élite eminentemente metropolitana y cosmopolita? El texto hace un repaso por la importante participación de la ciencia social boliviana, que a partir de una crítica a la política económica neoliberal, y nutriéndose de aportes especialmente pensados en lugares de enunciación contextuales, se fue desarrollando un planteamiento en torno a un relato de carácter plurinacional y comunitarista.

El rol de los intelectuales tiene además una clave y fundamental contribución en los cargos de administración del Estado, que bajo sólidos criterios de democracia participativa, se permitió la generación de instancias deliberativas en búsqueda de una convergencia de relatos que circulaban respecto al dilema cultura occidental v/s cultura originaria, y la disputa entre centralismo y el regionalismo. Estas convergencias dieron forma a las entidades políticas que finalmente conducen el proceso de cambio. Al mismo tiempo, el autor señala la necesidad de poner paños fríos a la aparente "contundencia" política de izquierdas en Latinoamérica. Siempre es un proceso reversible, especialmente en un escenario abierto y global.

El editor cierra el libro con el juego de palabras: "Los saberes de la revolución o la revolución de los saberes". Realiza una primera distinción entre cuatros tipos de saberes, el saber académico, el saber consultorial -en constante expansión y desplazando al saber académico-, el saber estatal y el saber popular. En Bolivia la revolución de los saberes se estaría desarrollando entre estos últimos dos, ¿se podría hablar de un diálogo entre el saber popular y el saber estatal? 
Finalmente, se presenta la bibliografía seleccionada -listado de 906 referencias-, correspondiente, en su gran mayoría, a libros de autoría boliviana, en función de lo que Los Amigos del Libro señalan: "No leer lo que Bolivia produce es ignorar lo que Bolivia es", dejando fuera de esta selección a revistas indexadas por decisión ético-política del editor del libro Juan Carlos Gómez.

Al concluir la lectura, nos podemos dar cuenta de que la pregunta inicial (“Bolivia hoy: ¿Una democracia poscolonial o anticolonial?”), por deliberada intención del editor no se ha respondido, aunque sí se descompone en algunos tramos del libro y se vuelve a componer en otros pasajes. Es difícil responder si alguna sociedad es anti o poscolonial, en virtud de la discusión teórica que lleva cuatro décadas, por mencionar por ejemplo los llamados "estudios poscoloniales". En estas discusiones se observa que lo anticolonial y lo poscolonial tienen distintas acepciones, especialmente para Latinoamérica, que en función de cada autor y/o cómo se entienda, son las primeras sociedades poscoloniales o simplemente no se les puede aplicar un concepto desarrollado en la mitad del siglo XX en otras colonias, otros continentes. Al mismo tiempo, el término puede denotar o un estado social o una actitud. De este modo se ha entendido por algunos autores, lo poscolonial como una reacción en respuesta al colonialismo y su legado, más que una sucesión de etapas. En consecuencia, no se podría hablar de sociedades poscoloniales sino de proyectos y movimientos colectivos poscoloniales. Fernando Coronil señalaba en 2004 que el intento de traer los "estudios poscoloniales" a Latinoamérica debía primero resolver su articulación con los "estudios latinoamericanos" donde la fuente basal de la cuestión "poscolonial” latinoamericana ha sido la teoría de la dependencia ${ }^{2}$. Desde esta lectura, las reformas estructurales en que las políticas provenientes de Washington de privatización, orientación a la extracción y exportación de materias primas, en el marco de gobiernos latinoamericanos autoritarios, pueden clasificarse como una neocolonización neoliberal o una nueva "colonización económica". Desde esta perspectiva las luchas antineoliberales pueden ser clasificadas como anticoloniales, dado el carácter colonizador del neoliberalismo. Así una situación posneoliberal, es a su vez una situación poscolonial. Ahora bien, esta fijación con amplio enfoque macro que acierta en las asimetrías y dinamismos globales, entre un centro y una periferia que antepone un norte y un sur, deja en una nebulosa el llamado colonialismo interno y nuestras historias no solo de asimetría, sino que también de genocidio. Así, el libro resalta el cómo hay una importante población indígena que no está completamente

2. Coronil, 2004. 
excluida de los circuitos económicos y sociales de la sociedad boliviana, es más, forma parte integral y deviene de una historia particular, en contraste con la mayor represión estatal hacia las naciones-originarias de la zona de oriente.

He ahí la importancia de este libro, en que se plantean las contradicciones de un proceso político con las vísceras expuestas. ¿Cómo conciliar las normas, las reglas y la nueva Constitución Política del Estado, y transitar hacia la inclusión y el reconocimiento del otro en una sociedad que se ha instituido en la asimetría y la exclusión? Por otro lado, el libro deja en evidencia cómo los apriorismos y recetas que se escuchan a menudo, estallan por superficialidad y la poca operatividad de su uso. En este sentido, el Editor señala que lo que se está viviendo es "un complejo proceso de cambios donde lo nuevo se confunde con lo ancestral y lo ancestral se confunde con lo viejo y con lo nuevo. El cruce de las temporalidades es total", donde las memorias largas y cortas sustentan la emergencia de nuevas identidades y nuevas luchas. Pese a ello, si bien no hay un modelo, las experiencias bolivianas nos llevan a observar una lógica más igualitaria en el tipo de relaciones establecidas. Es más, se replantea la lucha por los derechos de los pueblos indígenas frente al proyecto nacionalista, aparentemente excluyentes el uno del otro, pero que en el caso boliviano se problematiza esa última afirmación.

\section{LUIS VIVERO ARRIAGADA Universidad Católica de Temuco, Chile ${ }^{3}$}

Resulta paradójico analizar y comentar un libro sobre Bolivia, cuando el candidato a la Presidencia de la República, el ultraderechista José Antonio Kast, está proponiendo el cierre de la frontera con este hermano país. Pero ello no es casualidad, pues en algo refleja el cómo miramos a Nuestra América desde el fin del mundo, desde una sociedad construida y constituida sobre la base de un proceso de conquista y colonización genocida y de la negación de nuestras raíces indígenas, donde la dicotomía civilización/barbarie, no fue sino la justificación para el exterminio de los pueblos originarios, en pos de una "modernización" que benefició principalmente a la oligarquía de ascendencia europea.

3. Trabajador Social, Doctor en Procesos Sociales y Políticos en América Latina, Universidad ARCIS. Académico e Investigador, Departamento de Trabajo Social, Universidad Católica de Temuco. 
Intentaremos resumir en pocas líneas las impresiones del libro "Bolivia Hoy: ¿Una democracia poscolonial o antineoliberal?, editado por Juan Carlos Gómez Leyton y publicado por Ediciones Escaparate. Este trabajo nos lleva un poco hacia esas discusiones que planteábamos en el párrafo inicial. Nos convoca a mirar Bolivia no solo en sus procesos históricos y sus proyectos políticos. Sino que a partir de esas ricas experiencias y actores que se van haciendo presentes y, que en el desarrollo del libro, van simbolizando esas diversas voces que nos interpelan a mirar y analizar críticamente nuestros propios procesos y proyectos históricos, políticos y culturales. Incluso, desafía implícitamente a reflexionar sobre nuestras subjetividades, contaminadas del racismo que se nos impuso, como diría Quijano, en la colonialidad del saber y del poder, expresado hoy en el nuevo patrón de poder.

Este libro en sus diversos pasajes, en sus laberintos e intersecciones, nos va mostrando esa América Latina profunda, la cual en la década del noventa parecía completamente entregada a la hegemonía del capital transnacional, como una expresión material del triunfo ideológico del neoliberalismo. Un momento histórico en que para muchos parecía el triunfo absoluto y una materialización de la tesis del fin de la historia. Donde apocalípticos e integrados, como diría Hopenhayn, miraban con cierta desazón la algarabía de las clases dominantes. Pero para sorpresa de las élites, vendrá una respuesta contrahegemónica. Los invisibilizados e invisibilizadas, los nadie como diría Galeano, se juntarán para levantarse contra quienes los oprimen material y simbólicamente. Así entonces, se inaugura el nuevo siglo, con las nuevas luchas sociales, un nuevo y paradigmático ciclo de luchas sociales, que como bien lo grafica el libro, entre otros eventos, marcaría un hito el levantamiento de indígenas y campesinos de Chiapas, y la primera gran marcha del EZLN el 1 de enero de 1994.

La emergencia de este nuevo ciclo de movilización social, también permite la visibilización de nuevos sujetos en un escenario multifacético de nuevas formas de luchas de clases, donde, en una suerte de resignificación del marxismo mariateguiano, se reinstala la cuestión del indio. El indígena será en este nuevo escenario, el sujeto político más relevante y que desplazará al clásico movimiento obrero de masas y, por antonomasia, a los partidos políticos tradicionales que representaban los intereses de aquella contradicción capital/trabajo.

La respuesta a la hegemonía neoliberal y colonialista en el caso de Bolivia, es el resultado de un proceso de la acumulación y rearticulación de fuerzas del movimiento indígena y campesino. Representa una cierta simbiosis de las experiencias y pragmáticas sociopolíticas entre los movimientos indígenas originarios, 
movimiento obrero, de mujeres indígenas y campesinas, con los partidos políticos tradicionales. Representa también una resignificación de las luchas de clases en clave indigenista. Es decir, una reinvención del marxismo clásico desde una perspectiva latinoamericana e indigenista y, en muchos casos, sin necesariamente declararse marxista. Una diversificación de sus orgánicas y sus prácticas políticas, todo lo cual permite que en los inicios del siglo XXI llegue a ocupar la presidencia de la nación un indígena: Evo Morales Ayma.

Así entonces, sobre el proceso contrahegemónico que se construye en algunos países de América Latina y el Caribe, señala el autor y editor de este libro, “marcan nítidamente un antes y un después", los cuales, "son acontecimientos fundantes, más allá de si son exitosos o no. Dan inicio a algo desconocido"4. Por lo tanto, coinciden los distintos autores y autoras de este libro, que se trata de un proceso, de un proyecto aún en construcción. Por lo mismo, tiene avances y retrocesos, que presentan tensiones y confrontaciones incluso al interior mismo de los movimientos que constituyen política, social y cultural del Gobierno Plurinacional liderado por Evo Morales.

En consecuencia, no podemos esperar que este proyecto, que sin duda representa una expresión de democracia antineoliberal, menos aún de manera categórica y sin matices ni tensiones epistemológicas y políticas, pueda definirse como un proyecto poscolonial o anticolonial. Más bien, este libro nos invita a ese debate, a una reflexión politológica y epistemológica en esa dirección. Es decir, el libro es coherente con lo que significa el proceso boliviano en términos políticos y epistemológicos. Parafraseando a Zavaleta Mercado, esa hermosa sociedad abigarrada, también se manifiesta en esta obra.

Para irnos empapando un poco de esta interesante discusión, el autor y editor del libro nos ofrece una serie de trabajos, muy diversos, tanto temáticamente, como en el origen de los mismos. Unos son resultado de estudios de casos particulares y remiten a experiencias concretas, y otros se ubican en un nivel teórico o conceptual. Sin perjuicio de ello, estos nos permiten ir conociendo las trayectorias que han tenido los diferentes procesos políticos en Bolivia, cómo se han ido rearticulando las relaciones de fuerza y cómo se han ido posicionando nuevos sujetos y actores políticos.

El hecho "político-ecológico" más reciente (2010-2011) es abordado por la profesora Dra. Elizabeth Jiménez Cortés en su trabajo titulado "El conflicto del TIPNIS y la reconfiguración de los movimientos populares en Bolivia post-constituyente".

4. GÓMEz, 2017, p. 17 
Este hecho, tensionó significativamente las relaciones al interior del Pacto de Unidad hasta romperlas, poniendo en riesgo la unidad en la base política del gobierno de Evo Morales. Ha sido una coyuntura política, marcada por tensiones entre los movimientos sociales, indígenas, originarios y otros movimientos populares. Pero al mismo tiempo, ha generado ciertas condiciones político-estratégicas para una salida al conflicto, lo que podría considerarse un nuevo triunfo del bloque político masista que es la base más importante de apoyo a Evo Morales. En términos gramscianos, el bloque histórico que hoy representa de mejor forma el proyecto antineoliberal.

Por su parte, la profesora Dra. Doris Johnson Barella nos invita a reflexionar sobre la experiencia de la acción colectiva del Movimiento Sin Tierra de Bolivia (MST-bo), y cómo este se ubica y se mueve en la constelación de fuerzas sociales que le dan dinamismo al proceso político boliviano. ¿Cuáles son los aciertos y errores que ha tenido el MST boliviano? es una pregunta que podríamos plantearnos para motivar la lectura de esta parte del libro. Y sin duda, lo primero que nos surge como inquietud es hacer un paralelo con lo que es el MST de Brasil. De hecho, la autora refiere a que su inspiración es el "espíritu y estrategia del Movimiento Sin tierra de Brasil (MST-B). El MST-bo desde su aparición en la contingencia política boliviana buscó el apoyo y contacto permanente con su homólogo brasilero, intercambiando experiencias, recibiendo asesorías, etc." ${ }^{5}$.

Otro capítulo que resulta provocador es el referido a "las comunidades interculturales y la política agraria del gobierno de Evo Morales", desarrollado por la profesora Dra. Fabiola Escárzaga. Un trabajo muy pertinente para tenerlo como referencia en el análisis del contexto chileno. Más aun teniendo como punto de referencia que este año se cumplen 50 años de la Reforma Agraria de Chile, iniciada en el gobierno de Eduardo Frei Montalva. Las actuales condiciones materiales y simbólicas que se configuran en torno al agro en nuestro país, las relaciones de fuerza y el nivel de organización y sindicalización campesina en nuestro contexto macrorregional, hacen de este capítulo un material muy propicio para polemizar intelectualmente con la estructura agraria del Chile actual.

Sin duda, el proceso boliviano ha tenido una diversidad de protagonistas y, entre ellos, las mujeres, quienes históricamente han cumplido un rol político fundamental. En los distintos momentos de la historia de Bolivia, el movimiento indígena y campesino ha tenido como actoras protagónicas a las mujeres, a pesar de que ello no siempre es visibilizado en los relatos historiográficos. De hecho, no está de más

5. JoHNson, 2017, p. 64. 
mencionar un movimiento que reivindica explícitamente el rol de la mujer, el movimiento "Mujeres presentes en la historia”, con más de 25.000 participantes; o el movimiento histórico, Confederación de Mujeres Indígenas Campesinas Originarias de Bolivia, "Bartolina Sisa", que junto al movimiento "Mujeres Creando", han sido magistralmente reseñados en este artículo por el profesor Dr. Andrés Leiva Guzmán.

Por su parte, el trabajo de la Dra. María Teresa Zegada presenta un panorama de las "Transformaciones políticas en Bolivia y nuevos sentidos de la democracia”. Un trabajo interesante teórico-conceptual que entrega elementos para poder comprender la construcción del Estado Plurinacional y las concepciones sobre democracia, "más allá de los reiterados marcos conceptuales concebidos al alero de las categorías de democracia burguesa contenidas en la literatura que inundan las bibliotecas o programas académicos de las ciencias sociales de nuestras universidades. Si bien hay referencias a las discusiones, distinciones y categorías de connotados politólogos europeos y latinoamericanos, como Bobbio, O’Donnel, Portantiero u otros, este capítulo nos convoca a buscar nuevas lecturas e interpretaciones sobre la democracia. Las innovaciones en las relaciones entre el Estado y el amplio espectro de la sociedad civil, avanza -no sin tensiones- a una forma de democracia radical, de la cual nos habla Ernesto Laclau. Aparecen en estas discusiones otros autores, que por estos lados tal vez son algo desconocidos o quien sabe, intencionalmente ignorados, como Luis Tapia, Zavaleta Mercado, e incluso otros que deberían ser un poco más conocidos como Atilio Boron o Enrique Dussel. Con la sola mención de cada uno de ellos, se nos interpela a repensar las nociones de Estado y Democracia. Nos provocan otras lecturas, otras nuevas interpretaciones.

El rol de los intelectuales y el proceso político boliviano, trabajado por el profesor Dr. Jorge Gibert nos lleva a la necesaria reflexión de la importancia de los intelectuales y las ciencias sociales. Nos entusiasma, por ejemplo, preguntarnos sobre el rol que las ciencias sociales han tenido en la Araucanía históricamente o en la coyuntura actual. En el trabajo del profesor Gibert, entre otros tantos elementos relevantes de tener en consideración, se destaca la participación política y aportes al sustento ideológico de algunos intelectuales como Álvaro García Linera, Raúl Prada y el grupo Comuna (del cual fue parte importante el filósofo y politólogo Luis Tapia).

Para ir finalizando, me parece necesario destacar que el libro da cuenta de uno de los más interesantes procesos políticos de América Latina, donde la clase subalterna más excluida (los y las indígenas y campesinos/as), llega a constituirse en Gobierno, encabezado por uno de los suyos. No hablamos de alguien que pretende "representarlos" o hablar por ellos y ellas, sino que uno de ellos, un indígena. En 
este pasaje de la historia reciente de nuestra América, cabe consignar que los sujetos subalternos no son una mera abstracción o una especie de entelequia. Su expresión material y simbólica en el devenir histórico está signada por avances, retrocesos y tensiones, propios de las condiciones materiales y las subjetividades, configuradas en una compleja síntesis dialéctica. Está constituida por sujetos y subjetividades, con los que convivimos a diario y de los cuales también somos parte. Por ello, mi invitación y reflexión final apunta también a visibilizar a esos sujetos individuales subalternos con los cuales nos relacionamos cotidianamente, y que en este microespacio de poder, también configuramos la dialéctica de oprimido-a/opresor-a. En nuestros microespacios, como determinación de las contradicciones históricas, también hay opresión, y si no visibilizamos esto, difícilmente avanzaremos en la construcción de un estado democrático, pos o anticolonial.

\section{JUAN JORGE FAUNDES PEÑAFIEL \\ Universidad Católica de Temuco, Chile 6}

La siguiente reseña del libro "Bolivia hoy: ¿Una democracia poscolonial o anticolonial? Seis estudios y una bibliografía seleccionada”, editado por el Dr. Juan Carlos Gómez, se presentará en dos partes: la primera en relación con la obra propiamente tal; y la segunda, en referencia al contexto académico que hizo posible este trabajo y vinculada con la historia íntima de los autores de capítulos, del editor y del autor de esta recensión.

\section{Primera parte, el libro "Bolivia Hoy: ¿una democracia poscolonial o anticolonial?..."}

El texto comienza con una presentación donde el Dr. Gómez Leyton, el Editor, hace una descripción político-histórica-regional, desde las democracias herederas de los gobiernos autoritarios y militares de los años 70’ y 80’ en América Latina, neoliberalizadas y de fuerte base extractivista/colonialista. Esa revisión se conecta con los acontecimientos emancipatorios de las últimas tres décadas, marcados por movimientos sociales y transformación social, iconizados por el EZLN en México en los 90’ y los procesos constituyentes de Ecuador y Bolivia de la primera década

6. Abogado, UACH; Doctor en Procesos Sociales y Políticos en América Latina de la Universidad ARCIS; Académico de la Universidad Católica de Temuco y Profesor del Doctorado en Estudios Interculturales de la misma universidad. 
del siglo XXI, con la "Guerra del Agua”, que nace en Cochabamba, el Caracazo y los indignados/descamisados argentinos del poscorralito, entre otros.

La presentación que hace el Dr. Gómez Leyton puede resumirse en el siguiente presupuesto por él planteado:

“... hay acontecimientos que adquieren significados y connotaciones excepcionales y reveladoras... señalan aspectos fundamentales de un nuevo ciclo de la lucha histórica de los pueblos latinoamericanos por la Democracia y, por sobre todo, el buen vivir"'.

Advierte que estos acontecimientos, epistemológicamente, requieren un tratamiento meticuloso por parte de las ciencias sociales críticas, "pues develan, probablemente, el futuro" ". Y, aunque el Editor no lo dice, su mensaje se explicita en el rigor académico de cada uno de los pasajes del libro que le siguen a dichas palabras.

Luego, para dar cuenta del paradigmático caso boliviano y del rol e impacto que en él jugaron los pueblos originarios, señala con vehemencia que ellos "plantearon la realización de una Asamblea Nacional Constituyente, democrática, incluyente y revolucionaria, con el objeto de refundar el Estado, la nación y la democracia"

En seguida, identifica de manera precisa dos cuestiones claves:

- Una, la existencia de 181 años de un Estado débil, en crisis, en "constitución" con 20 procesos constituyentes fallidos.

- La segunda, las causas de esta crisis constituyente" permanente", ubicadas en la incapacidad de las (tres) constituciones precedentes de resolver los grandes clivajes de la sociedad de Bolivia que sintetiza en tres factores críticos:

- "la presencia de pueblos originarios";

- "el regionalismo" autonomista;

- "los antagonismos de clases", entrelazados en las décadas previas al Estado Plurinacional, con la llamada "democracia pactada", que describe como pseudosistema democrático oligárquico que fue turnando en el poder a partidos políticos que terminaron en crisis por falta de representación y legitimidad ante las grandes masas sociales oprimidas, pobres y, en especial, excluidas del poder político.

7. GÓMEZ, 2017, pp. 17-18.

8. Gómez, 2017, p. 18.

9. Gómez, 2017, p. 18. 
Conforme con este análisis, describe dramáticamente a Bolivia como un "estado fallido", una "Nación ficticia”, un "Estado sin Nación”, lo que encaminó el proceso constituyente reciente que tuvo que "refundar el Estado de muchas naciones y pueblos". Dice Gómez: se trató de la más "revolucionaria de todas las demandas sociales, políticas y culturales planteadas por los sectores subalternos y dominados desde la revolución francesa de 1789 a la fecha" ${ }^{10}$.

Así, el caso boliviano, que este libro nos presenta, permite retomar conceptos fundamentales, planteados por Gramsci en su momento, y por Laclau y Mouffe en décadas más recientes -como bien lo desarrolla Zegada en su capítulo-. Estos planteos nos obligan a repensar la "lucha de clases", más allá de los referentes obreros, de categorías como el "proletariado", para pensar "la lucha de clases", más desde su significado contrahegemónico, más desde la ruta emancipatoria, que desde una composición social o (en nuestro caso) étnica determinada, dada la extensa y diversa geografía humana y política de Latinoamérica, impactada por el mercado de la sociedad global neoliberal.

El Editor, entonces, nos invita a pensar la Revolución desde la más abigarrada (recurso de Zavaleta que atraviesa la obra) de las sociedades latinoamericanas. Nos anima a entender el socialismo en su sentido profundo y no solo en sus propuestas orgánicas pero sin prescindir de los laberintos de la construcción ("nada de sólida”) del Estado Plurinacional.

Por último, Juan Carlos Gómez destaca dos grandes momentos del proceso sociopolítico boliviano reciente: aquel iniciado por la "Marcha por la Dignidad de 1990" que abrió los horizontes para las transformaciones que se desencadenarían una década después con la "Guerra del Agua” de 2000 (como detonante histórico) que concluye con una nueva Constitución. Proceso que en su conjunto alegoriza como aquel tiempo de "revolucionar lo existente". Y, el segundo, a partir de 2010, en que -en sus palabras- "se trataba de gobernar la Revolución"11.

Estos dos grandes momentos o procesos serán fundamentales para entender el análisis que los autores formulan en sus respectivos trabajos y el aporte sustantivo de la obra en comento para las ciencias sociales latinoamericanas, según lo sostiene el propio Editor.

En este sentido, me atrevo a postular que la contribución de estos trabajos no radica en una revisión más de los laberintos históricos y políticos de la “Guerra

10. Gómez, 2017, p. 18.

11. Gómez, 2017, p. 23. 
del Agua" o del proceso constituyente, sino que su aporte debiera referir a aquello que pueda decirse de la construcción institucional en el escenario revolucionario plurinacional post-constituyente, sobre el gobierno y el desgobierno de lo recién constituido. El potencial aporte será sustantivo si el libro logra mostrarnos que es posible una forma de socialismo, una dinámica que articula conflicto y diálogo, que conecta movimientos, partidos, luchas sociales irresolutas, conflictos indígenas y el subsistente extractivismo público y o privado. Si se nos muestra cómo se han jugado las formas de la democracia representativa, cruzadas por dinámicas impensadas de control popular (como "el gasolinazo" de 2011); si se nos explica, también, el rol que juega el carisma que reflota en una praxis que ha desmitificado parte de la politología (sobre el populismo), pero donde también el poder no ha contenido sus lados oscuros, mostrándonos que democracia y autoritarismo, que estrategia e idealismo, que legitimidad y estabilidad, que solidaridad y clientelismo, cruzan sendas y también pueden seguir caminando juntos al alero de la polisemia democrática.

La decisión sobre si se cumple la expectativa o no será de cada lector.

De esta forma, cuál debiera ser el "peso específico" de este libro en un marco de una muy extensa bibliografía del caso boliviano, quien sabe si "sobreestudiado". Cómo estimar la importancia de este libro y ver si merece ser destacado por sobre las 906 referencias bibliográficas que el mismo texto ofrece en su capítulo final. Esta potencial contribución podría radicar, precisamente, en lo que se nos pueda presentar y reflexionar en torno a la segunda década del siglo XXI. En cómo la obra nos muestra esta "revolución política" que no ha logrado emanciparse del patrón de acumulación capitalista; en cómo nos explica o describe el "indianismo andinoamazónico”, aquel enfrentamiento andinomasista desarrollista, con el movimiento de los pueblos originarios amazónicos y su defensa de la intangibilidad territorial; en fin, en su capacidad de explicar cómo es posible articular una democracia contrahegemónica y contener los abismos de la nueva hegemonía.

Algunos elementos comunes que emergen del conjunto de los trabajos presentes a lo largo del libro los encontramos en las estrategias de coaptación y clientelismo del MAS, en sus transacciones con los sectores de la vieja oligarquía, en la aprehensión de los discursos de los movimientos en aras de una gobernabilidad sobre aguas inestables.

Encontramos algunos ejemplos cuando se nos muestra la falta de voluntad (quizás de capacidad) del gobierno de Evo Morales -con diversos matices históricocontextuales- de avanzar en la profundización de las reformas vinculadas a la que el mismo Gobierno llamó inicialmente como la "Revolución agraria”, basada en la política de "colonización" de las que llegaron a llamarse "comunidades 
interculturales". Aunque esta política implica un claro cambio de enfoque, al asumir "la reversión" ("expropiación") como instrumento en los casos fragrantes de latifundio que cambió la geografía política, humana y social (involucra a un millón de "colonizadores interculturales"), por su propia envergadura y complejidad ha sido, lento y vertical y no "desde abajo", como fue en la propuesta política.

Otro aspecto que se destaca, en el libro y en el proceso sociopolítico -que bien explica Escárzaga-, "es la cancelación del carácter autónomo de la acción política” de las organizaciones sociales, que ella describe desde la experiencia de los que denomina "colonizadores interculturales". Esta pérdida radicaría, precisamente, en la coaptación y el clientelismo, centrando el accionar político mediante la adscripción “al MAS, al Gobierno y al presidente Morales", lo que, en definitiva, al perder poder en sus aliados sociales, terminó debilitando "la propia fuerza del Gobierno para enfrentar a sus mayores enemigos, la derecha oligárquica del Oriente" ${ }^{12}$.

Por otra parte -como destaca Leiva- las agendas del feminismo en Bolivia están marcadas por el "papel del gobierno masista en su intento de incluir en sus marcos ideológicos y normativos los contenidos de las luchas feministas o de mujeres, con el objetivo de controlar las luchas posibles y sus horizontes políticos”. Luego, institucionaliza la agenda antipatriarcal, como si el patriarcado fuera un producto exclusivo del Colonialismo, "volviéndolo funcional e instrumental a la 'línea editorial' del Gobierno”, negando así la diversidad de demandas, "pero sobre todo asegurando que aquellos movimientos no 'imaginen' un mundo distinto al que el Gobierno está interesado en promover”.

No obstante -en el permanente diagnóstico dual del ser y quehacer boliviano- el estupendo trabajo de Leiva nos muestra cómo las "bartolinas” y "Mujeres Creando", en tanto significaciones que cambian lo que las mujeres pueden ser o no en la sociedad boliviana: "impiden que se produzca un cierre en un contenido -cualquiera que este sea- sobre lo que "es o no es" la mujer, si no que abren a interrogación lo instituido, a fin que sean las mismas mujeres las que tengan el poder de instituir y cambiar sus sentidos.

Más centrados en el ideario del libro se visualizan los enfoques del PROSPAL ${ }^{13}$, por ejemplo, con la presencia explícita de la matriz "Estado, Mercado y Sociedad", defendida por Gómez Leyton para la América Latina del siglo XXI, en la idea de la

12. Escárzaga, 2010, pp. 127-128.

13. Doctorado en Procesos Sociales y Políticos en América Latina (PROSPAL), de la Escuela Latinoamericana de Estudios de Posgrado (ELAP) de la chilena Universidad de Artes y Ciencias Sociales, ARCIS. 
irrupción hegemónica del mercado en las sociedades latinoamericanas, que surge -académicamente- de una respuesta al esfuerzo de Manuel Antonio Garretón con su "matriz sociopolítica" -como él grafica: ya "descuajeringada"-14. A diferencia de Garretón, Gómez deja atrás el derrotero de los partidos políticos tradicionales, oligárquicos, de clase, para buscar nuevas comprensiones de la realidad sociopolítica que bien ofrece el escenario/laboratorio boliviano plurinacional, post-constituyente, democrático sin duda, de inspiración anticolonial y de resúmenes con aromas poscoloniales.

De esta forma, la obra, tanto nos permite develar los nudos irresolutos de la Bolivia plurinacional, como asimismo, da cuenta de caminos, rutas que pueden ser leídas y revisadas, para las propias cartografías políticas de las demás sociedades latinoamericanas.

Ya situados en los seis estudios del libro, es posible formular algunos comentarios específicos. El primer capítulo de Elizabeth Jiménez, refiere quizás al más complejo y aún abierto de los conflictos bolivianos, aquel que muestra toda la debilidad de la "Revolución” y que da cuenta de las “dos Bolivias”, el TIPNIS.

En este caso han colisionado discursos y praxis política. Pueblos que estuvieron en el corazón de la reconstrucción plurinacional, que fueron parte fundante del pacto constituyente (Pacto de Unidad), fracturados de la sociedad y del Estado, que han sentido el peso del patrón de acumulación capitalista subsistente de la mano del mismo Estado Plurinacional. Se trata de una suerte de paradoja y pesadilla democrática en que los pueblos indígenas, aunque han cambiado las formas, siguen siendo los oprimidos y los que deberán "pagar el desarrollo", esta vez de la mano del "hermano Indio", "El Evo".

Entonces, retomando las premisas enunciadas para estimar los potenciales aportes del libro -esto es, qué nos dice del proceso post-constituyente, de lo poscolonial versus lo anticolonial-, este primer artículo, muy bien escrito, ameno y de muy buenas fuentes, describe con acierto el caso o más bien el campo sociopolítico (en términos de $\mathrm{Zegada}^{15}$ ) asociado al caso del TIPNIS. Sin embargo, al mismo tiempo, es posible decir que, a lo menos, es breve en sus reflexiones de lo actual y de lo por venir. Aunque no por ello menos crítico. Así, se puede destacar este trabajo (el caso TIPNIS) como un buen diagnóstico de las "contradicciones de la Revolución” plurinacional de Bolivia, que invita a seguir los entramados de los trabajos siguientes.

14. Garretón, 2010.

15. ZEGADA et al, 2011. 
El segundo capítulo preparado por Doris Johnson Barella refiere al Movimiento de los Sin Tierra en Bolivia (MST-bo). Aunque, como bien explica, la cuestión de la propiedad de la tierra cruza la historia política de Bolivia, el estudio se centra en esta expresión de acción colectiva (MST-bo) en dos períodos: 2000-2005 y 2006-2009.

Aunque la lucha por la tierra estructura buena parte de la historia social y política boliviana, las luces y guirnaldas constituyentes, el destello del "presidente indio", el gobierno de "Los movimientos sociales", quizás han "quitado brillo" a un capítulo histórico social fundamental ${ }^{16}$.

Como señala la autora la radicalidad del movimiento boliviano de los sin tierra se encuentra en "sus estrategias de acción colectiva... y en representar y liderar las acciones de resistencia de los sectores campesinos más marginales y excluidos contra el poder que emana del control territorial". El trabajo el MSTbo se organiza en "una acción política de resistencia y movilización destinada a desestabilizar ese muro de contención y dominación que representa la concentración de la tierra" ${ }^{17}$.

Este trabajo retoma la senda que nos permite ir develando en mayor medida las contradicciones del campo político boliviano. Se empieza a delinear un eje común en los escenarios estudiados, aquel momento de la emergencia social, a partir del año 2000 (el efecto “expansivo social” de la "Guerra del Agua”) y "el declive y marginación del Movimiento de MST-bo de la contingencia política boliviana, que estará marcado por la llegada del primer Gobierno de Evo Morales y el término del proceso constituyente". La crisis orgánica, la revolución contrahegemónica y "el gobierno de la revolución" que bajo el nuevo discurso hegemónico del Estado Plurinacional, contiene y desarticula los movimientos sociales. Todo esto, marcado por una palmaria afirmación de Doris Jhonson: "ni en sus momentos más álgidos tuvieron la capacidad para influir en la transformación de las relaciones de producción" ${ }^{18}$.

En tercer lugar, Fabiola Escárzaga, desarrolla su estudio de "Las comunidades interculturales y la política agraria del gobierno de Evo Morales (2006-2009)". La autora nos muestra otro campo político boliviano dado por las políticas de colonización, hoy, del Estado Plurinacional, de las denominadas "comunidades

16. Gómez, p. 65.

17. Johnson, 2017, pp. 67-68.

18. Johnson, 2017, pp. 62, 85. 
interculturales", que corresponden a "nuevos asentamientos de migrantes quechuas y aimaras del occidente del país en territorio amazónico” (Pando) ${ }^{19}$.

No puedo dejar de referir al concepto de interculturalidad que propone la autora y que le sirve de marco de análisis, en tanto la interculturalidad:

“... expresa al establecimiento de relaciones de respeto y aceptación entre personas de culturas diferentes en contenido y jerarquía; es decir, a la superación del conflicto étnico mediante la aceptación de la diversidad existente y la desaparición de las jerarquías sustentadas en la diferencia cultural”20.

Una segunda cuestión de base que nos advierte es que en la actual coyuntura política de Bolivia, el uso del término intercultural se refiere "a las relaciones conflictivas entre sectores indígenas y populares diferentes de Bolivia” y ya no se dirige solo a las relaciones de conflicto entre la "cultura blanco mestiza" y "las culturas indígenas subalternas” ${ }^{21}$. Al respecto, es destacable cómo Escárzaga muestra una dimensión de la interculturalidad poco conocida y estudiada, aquella "entre pueblos", entre "identidades culturales indígenas", entre culturas subalternas, bajo el factor común de la resistencia a la subordinación blanco-territorial. Así, los colonizadores campesinos, mestizos, de ascendencia aimara y quechua, los llamados "collas", migrantes internos desde las tierras altas andinas a las tierras bajas del oriente amazónico (los "collas" son reconocibles en la geografía humana urbana de tierras bajas, ya que por décadas no radicados, deambulan, pobres entre los pobres, por las calles cruceñas y del oriente boliviano). Mientras en el oriente, las comunidades nativas luchan por la recuperación de sus territorios, en una relación estratégica con los terratenientes que defienden sus propios intereses, pero también procuran usar las demandas indígenas nativas para fortalecer su posición frente al gobierno.

Se trata de un campo de conflicto -finamente descrito por Escárzaga-, entre la lógica de "colonización” (de las basta regiones amazónicas de Pando), de la reconstrucción nacional, de la "Nación boliviana”, que entra en abierta contradicción con el discurso hegemónico y proyecto político del "Estado Plurinacional”. Así, aquí, los mástiles plurinacionales enarbolan la bandera del Estado nación boliviano para justificar la protección de la "soberanía” boliviana en las tierras bajas amazónicas. $\mathrm{Al}$ respecto, no deja de llamar la atención cómo el discurso del Estado nación,

19. Escárzaga, 2017, p. 105.

20. Escárzaga, 2017, p. 105.

21. Escárzaga, 2017, p. 106. 
de la Nación boliviana emerge desde el propio Gobierno Plurinacional, de la mano de su "hermana de placenta ideológica", la soberanía nacional. Este objetivo estratégico se presenta en un sentido externo, respecto de países vecinos como Brasil (campesinos sin tierra y también industria ilegal o contrabando), pero especialmente en relación a la soberanía interna, frente a la agenda autonomista "camba", de la oligarquía agraria de oriente que le disputa la hegemonía en el territorio, no solo al gobierno, sino que al proyecto político del Estado plurinacional que ha venido mermado sus intereses.

Este proyecto de colonización prioriza "la construcción de la nación mestiza", proyecto fracasado por las élites blanco-mestizas”, mediante una actualización del "proyecto nacional popular" histórico. Luego el proyecto indígena que fue soporte para la construcción del Estado Plurinacional, que llevó a Evo Morales al Gobierno, es subordinado bajo el proyecto nacional popular gubernamental.

Se nos devela una tensión y un futuro incierto de conflictividad interétnica, entre indígenas nativos amazónicos e indígenas sin tierra migrantes internos. Conflicto que es agravado por el interés político desestabilizador terrateniente que ve en esa potencial crisis una oportunidad de reposicionamiento de su proyecto económico y político.

A continuación, Andrés Leiva Guzmán investiga "los imaginarios sociales en torno a la participación política, de dos movimientos colectivos de mujeres situados en Bolivia": "Bartolina Sisa" y "Mujeres Creando". Indica que su trabajo procura "dar cuenta de articulaciones de sentido que pueden ser reconocidas en producciones discursivas... que por sus características son necesarias de poner en cuestión", porque desde ellas se "instituyen formas de orientar y conducir las estrategias políticas de sus agendas feministas o de transformación de la sociedad" 22 . Con este fin se pregunta sobre el papel del feminismo o del movimiento de mujeres en el proceso político actual boliviano, representando desde ya la multiplicidad de sentidos que puede tener el movimiento en relación a la diversidad de proyectos. Luego, especifica un sentido en particular: ¿cuál es el lugar del feminismo en el movimiento social y político boliviano y sus transformaciones?, ¿cuál ha sido el grado de influencia que el enfoque feminista ha tenido en el movimiento de mujeres y en otros espacios de interacción social?

El autor critica la "masculinización” de "Bartolina Sisa” -"mujer-héroe"-, en tanto se traduciría en la masculinización del proyecto de millones de mujeres

22. Leiva, 2017, p. 133. 
bolivianas que reúne este movimiento ${ }^{23}$. Dice al efecto que es "el discurso de las bartolinas el medio indígena que aparece como lugar donde se podrían efectivizar las demandas por igualdad del feminismo", pero que ello "no reconoce las condiciones de exclusión por razones de sexo género en el mundo indígena" ${ }^{24}$. Así este aparece como un lugar ideal, ocultando su desigualdad de poder que no es distinta que en el resto del mundo.

El autor afirmará que las mujeres y sus logros de inclusión en el ámbito político, serán tomados como un logro del movimiento indígena que se abre a la inclusión y no en una consecuencia de la lucha de las mujeres, como una conquista de las “mujeres indígenas”. Desde su crítica a las bartolinas sostiene dolorosamente que las mujeres "no pueden articular sujeto", sino que son habladas por el orden social mayor, desde antes y para siempre, pasando a ser un "contenido" que solo tiene valor en relación con dicho orden. Se trata de un orden que "niega su habla" porque habla desde el orden patriarcal.

Respecto de "Mujeres creando" explica que este movimiento de mujeres, visualizadas mediante el grafiti y otras acciones de protesta urbana, desde el trabajo con comunidades indígenas, asume la representación de mujeres indígenas, prostitutas y lesbianas, pobres, explotadas y marginadas, por el capitalismo y la sociedad patriarcal. Se trata de la bandera de las mujeres de "todos los colores, razas, condición económica $[y]$ orientación sexual". Se trata de una agenda que evita la "victimización" y la coaptación por el poder de su propia protesta ${ }^{25}$.

Luego el autor desarrolla una aguda crítica en torno a la figura de su líder y representante, María Galindo, quien ha concentrado en su persona, historia y discurso y el proyecto del colectivo y su discurso como grupo, invisibilizando la diversidad de mujeres que forman parte del movimiento y que ese proyecto representa.

Mediante una protesta que el autor califica de radical, binaria ("buenos y malos") que se levanta desde la comodidad "de la autodefensa de la identidad propia”, la resistencia a la coaptación del poder político, se transforma en un lugar de superioridad moral al que -paradójicamente- nadie de los movimientos de

23. La Confederación Nacional de Mujeres de Campesinas, Indígenas originarias de Bolivia: Bartolina Sisa, es la mayor agrupación de mujeres indígenas de Bolivia, busca organizar, potenciar y convertir a las mujeres en líderes locales, fundadoras del MAS-ISP y aliadas del Gobierno de Evo Morales, aparecen en el discurso de gobierno "como un ejemplo de lo que la gestión del MAS ha hecho en materia de la lucha de mujeres" describe Leiva.

24. Leiva, 2017, p. 145.

25. Leiva, 2017, p. 148. 
mujeres puede alcanzar, "reproduciendo la lógica de exclusión de la que buscan salir y revertir" ${ }^{26}$.

Destaca de ambos movimientos, tanto su crítica a las visiones de género y del feminismo (clásicas y neoliberales); también, la búsqueda en ellos de una identidad femenina alterna -desde sus respectivos referentes- como nuevo modo de entender y significar "cómo ser mujer en la sociedad boliviana".

Con todo, ante la iconización heroica y masculinizada de "Bartolina Sisa" y la concentración escénica de María Galindo, les reclama a ambos movimientos que sin reconocer el valor, los significados de cada mujer en sí misma "difícilmente podrán revertir su situación de explotación o de desigualdad de poder frente a los hombres" ${ }^{27}$.

El trabajo de Jorge Gubert Glassi, con su estudio "El rol de los intelectuales y el proceso de cambio político boliviano", muestra el rol activo y trascendente que ellos han tenido en el caso de Bolivia. Explica que estos intelectuales plantearán una refundación de la nación y del Estado, desde la crítica al sistema económico neoliberal, la crítica al énfasis institucionalista en la administración del Estado y que la esta Ciencia Social boliviana dio paso a nuevas performaciones de la democracia, como la participativa, que inspiró al MAS y llevó a algunos de los mismos intelectuales al Gobierno.

El autor, bajo la oferta de revisar el rol de los cientistas sociales en los procesos bolivianos, más bien presenta una revisión y teorización del rol de los intelectuales cientistas sociales en América Latina, a lo menos desde la segunda mitad del siglo $\mathrm{XX}$, que bien vale la pena ser leída y comentada en capítulo aparte, que queda pendiente en esta reseña.

El trabajo de Marité Zegada, “Transformaciones políticas en Bolivia y nuevos sentidos de la democracia”, muestra una visión general de lo que ha denominado el "campo político boliviano" que resume sosteniendo que la crisis del sistema político plasmada en la Guerra del Agua y a partir de ella, implicó una renovación de las élites políticas y la sustitución de la concepción democrática previa (pactada, oligárquica), por una nueva fórmula democrática constitucional (2009) que llama “ 'democracia intercultural' como horizonte político" cuya incorporación en la práctica institucional de la política aún es limitada ${ }^{28}$.

26. Leiva, 2017, p. 151.

27. Leiva, 2017, p. 153.

28. Zegada, 2017, p. 161. 
Inicia su trabajo con un marco teórico sobre la concepción de la democracia, sostenido desde los presupuestos de Lefort, Laclau y Mouffe -en el que coincidimos de manera relevante- que supone la democracia como "la disputa política estructural entre principios hegemónicos distintos que pugnan por el poder y por (re)articular los elementos ideológicos de la coyuntura", en relación con los respectivos discursos políticos disputados en el campo sociopolítico. Asimismo, como ocurrió con/tras la Guerra del Agua, nos dice que "en situaciones de crisis, al perder su capacidad de interpelación hegemónica, se produce un proceso abierto de circulación de distintos elementos discursivos y se abren nuevas posibilidades de (re)articulación" 29 .

Desde Zavaleta, plantea breve y diáfanamente la evolución democrática boliviana, en especial los límites importantes del modelo democrático representativo frente a la "abigarrada" sociedad de Bolivia, a la par del inacabado proyecto del Estado nación (potenciado desde la Revolución de 1952) que buscaba la integración social, política y cultural, en esta sociedad compleja que configuró el cuestionamiento de la "comunidad imaginada" y el "espejismo del mestizaje", que contrahegemónicamente llevó a la transformación sociopolítica articulada desde el año 2000.

En su mayor parte, el texto de Zegada, con un exquisito manejo de fuentes (clásicas y latinoamericanas emergentes), hace un recorrido por las concepciones democráticas, para centrarse en las versiones “antagonistas”, críticas al modelo representativo liberal, que asumen la articulación democrática agonística, desde los conflictos, desde la materialidad social, económica, política y cultural. En este sentido, Zegada, sin despegarse de la experiencia del campo político boliviano y en buena medida desde el aprendizaje que arroja dicha experiencia -como ha sido su bibliografía en un marco más amplio-, desarrolla un texto que bien puede ser un manual, un documento informado y sistemático que permita comprender los sentidos, bases teóricas, prácticas y políticas de una nueva forma de democracia, profundizada y en contexto latinoamericano. Y -nos atrevemos a decir, sin restar mérito a los caminos emancipadores trazados por Laclau-, explica de manera diáfana y breve, lo que nos entregó Laclau de forma extensa y, a veces, algo oscura. El modelo democrático descrito por Zegada no prescinde de la democracia representativa, pero la cuestiona y amplía -parafraseando su obra prima- "desde los márgenes”, relevando en todo esto el complejo desafío de la institucionalización, de formas de "gobernabilidad que se verifiquen en el campo político", lo cual viene siendo, en definitiva, el desafío de "Bolivia Hoy"...

29. Zegada, 2017, p. 163. 
Por último, se destaca el extraordinario capítulo bibliográfico final que suscribe el Dr. Juan Carlos Gómez. Este precede la selección bibliográfica con un ensayo sobre la producción de conocimiento y el "saber" en estos tiempos "postanticapitalistas". Camina desde "el saber en la revolución", como "revolución de los saberes", para categorizar el saber consultorial, el académico, el estatal y el popular. Propone rescatar el libro como artefacto literario, moderno, genuinamente democrático, "portador de ideas y saberes diversos", mientras, formula una crítica franca al neoliberalizante "pensamiento único" del que bien pudo haber llamado "saber indexado" -le dejo la propuesta-.

La bibliografía seleccionada de 906 obras -en la que agradezco la menciónconstituye una verdadera hoja de ruta para futuros investigadores cuya revisión resultará inexcusable de aquí en más, si se busca investigar en torno a los procesos sociales y políticos latinoamericanos, será fundamental para "pensar en contexto".

Con la finalidad de cerrar esta primera parte, presentamos una reflexión de lo que podemos denominar sobre una "densidad paradójica".

El caso de la transformación sociopolítica en el Caso de Bolivia, en especial como escenario de reconocimiento de los pueblos indígenas en América Latina, se caracteriza por su densidad y complejidad, tanto desde sus raíces históricas, como por sus fracturas contingentes. En efecto, según Xabier Albó, estos quiebres se pueden alegorizar como el gran clivaje de "las dos Bolivias", conforme el cual "el Estado y la sociedad boliviana están cruzados, entre otros, por un clivaje central llamado de la 'Bolivia Globalizada versus la Bolivia profunda'”. Luego, bajo la expresión de "las dos Bolivias" subsiste un nudo de clivajes que envuelve la sociedad boliviana - "varias versiones entrecruzadas de esas dos Bolivias polarizadas"- dice Albó $^{30}$. Explica que se trata de una fractura cultural, de "dos Bolivias", una posterrateniente, blanca, agraria o burguesa, conflictuada con otra originaria indígena y mestiza, a su vez múltiplemente subdividida e interconectada, con una diversidad y complejidad que supera la simple visión dual. Emerge la Bolivia "urbana versus la global; la rica versus la pobre; la "colla" o andina versus la "camba" u oriental" 31 , tierras altas versus tierras bajas. Y todo ello hay que verlo desde el proceso social y político posterior a la "Guerra del Agua”, el MAS-ISP, el Pacto de Unidad, la Constituyente y los respectivos gobiernos de Morales.

30 Albó, 2004, p. 150.

31 Albó, 2004, p. 150. 
Es necesaria esta advertencia porque el libro "Bolivia hoy: ¿una democracia poscolonial o anticolonial...", se sumerge y subsume en y con estas fracturas de las diversas Bolivias. Ello, sin duda, lo dota de una riqueza extraordinaria, tanto en las respectivas síntesis histórico-políticas de cada uno de sus estudios, como en sus reflexiones críticas en torno a ellas y sus lecturas de la gobernabilidad masista. Entonces, la obra, sin duda, debiera permitir, primero, a un lector inicial formarse una visión general del proceso sociopolítico que llevó a constituir el Estado Plurinacional de Bolivia y, también, conocer las visiones críticas que existen en torno a su instalación y a los 15 años de gobierno de Evo Morales junto al MAS-ISP. Sin embargo, decimos "debiera", porque el libro, al recoger la densidad y complejidad del proceso, aunque ameno de lectura, contiene una - quizás- inaprensible carga informativa, sucesivas reflexiones críticas -bien pensadas y formuladas por cierto-, que mientras informan, empiezan a alejar el análisis del lector inicial y lo acercan al lector informado, al investigador. Más bien, a los investigadores en las respectivas áreas de cada uno de sus estudios, incluimos las reflexiones de Gómez Leyton que -en una tarea de edición estratégica- operan como el entramado general que le da armonía al trabajo.

Con todo, era imprescindible e inevitable asumir esta "densidad paradójica" si se quería contar esta historia y el Editor lo ha tenido en claro, recogiéndola con coraje académico, confiado en que tenía la "armas para hacerlo", en los autores y sus tesis "prospalianas”, destacando, por cierto, a Marité Zegada, maestra y alumna, más los aportes de la profesora Escárzaga y el profesor Gibert.

\section{Segunda Parte. La gratitud una necesaria compañera del conocimiento...}

Buscando explicaciones para la cuestión del "orden social”, "del reconocimiento", tratando de entender y explicar cómo y en qué sociedad vivimos, Norbert Lechner (desde América Latina) y Axel Honneth (desde el Viejo Mundo), coinciden en que la explicación, la articulación, de la dimensión política, de la deliberación en lo social, antes que a toda cuestión de derechos, supone la dimensión subjetiva, íntima de los sujetos. Aquella de las víctimas, de quienes viven el menosprecio y el prejuicio.

Advierto aquello, porque las virtudes del libro "Bolivia Hoy..." que tengo el honor de reseñar, podrán emerger por sí mismas, respaldadas por el prestigio académico de sus autores. Sin embargo, es preciso detenernos en la cuestión prepolítica o aparentemente prepolítica, la de los sujetos, la de aquellos que se simboliza con este libro. Y digo aparentemente prepolítica, porque su subjetividad encarnada no le quita nada al profundo legado emancipatorio de que da cuenta esta obra, simbolizado 
en los dos "exprospalianos" que suscribimos estas recensiones, que cursamos el PROSPAL en wallmapu, en el territorio mapuche de Temuco, en la provincia desde siempre excluida del conocimiento por la agencia académica hegemónica.

Personas como nosotros y probablemente la mayoría de los hoy doctores "prospalianos", como, entre muchos, los temucanos Lucy Ketterer, Eduardo Escalona San Martín, Luis Vivero, Alonso Azocar. Por qué no decirlo, y los de Colombia, de Bolivia y los de Venezuela, con alta probabilidad no seríamos Doctores, con el impacto que ello tiene en lo personal. Y, sin duda, no seríamos este "tipo de doctores". No seríamos agentes de cambio emancipador, con las siempre potenciales consecuencias que ello, de una u otra forma, puede terminar teniendo en nuestras sociedades y bien se escudriña en uno de los trabajos del libro "Bolivia hoy...".

Estos logros académicos están lejos del acaso, porque detrás del proyecto académico del PROSPAL están las convicciones antihegemónicas de un equipo de académicos, como el Doctor Gómez Leyton, Editor de la obra reseñada y Exdirector de dicho doctorado, más el esfuerzo -en diversos momentos- de Gabriel Salazar, Manuel Antonio Garretón, Igor Goicovic, María Eugenia Valenzuela, María Magdalena Valdivieso, Carlos Durán, entre muchos, quienes creyeron la adelantada idea de dictar un doctorado en ciencias sociales en Temuco. Se propusieron ofrecer el mismo doctorado santiaguino (no una versión "sucedánea provinciana") en las lluviosas tierras sureñas en una auténtica forma de emancipación política en la academia.

La tarea no fue sencilla porque la propia institucionalidad local cerró puertas, pero, por sobre las universidades y sus cierros patriarcales, agradecimiento sincero y homenaje propio merecen aquellas que creyeron en este proyecto, las compañeras de la "La casa de la Mujer" que cobijaron el Doctorado del PROSPAL en los años de sesiones temucanas y, entre ellas, nuestra mención imprescindible para nuestra compañera y amiga, la doctoranda, Fresia Cea, cuya graduación ha de ser en otra dimensión, aquella del reencuentro y del amor que le fue privado en la Tierra.

Así, en las horas de la muerte progresiva y neoliberal del Proyecto Político Académico de la Universidad ARCIS, a la que tanto y tantos debemos, este libro “Bolivia Hoy: ¿Una Democracia Poscolonial o anticolonial?” emerge como un necesario y muy oportuno homenaje en el que confluimos desde nuestros respectivos mundos de la vida, para decir con humilde orgullo: gracias Doctorado en Procesos Sociales y Politicos en América Latina, gratitud para el PROSPAL y para la Universidad de Artes y Ciencias Sociales, hasta siempre ARCIS...

Temuco, 17 de octubre de 2017. 


\section{Referencias bibliográficas}

Albó, Xavier. (2004). Indentidad y acceso indígena al poder. En Memoria del Foro Internacional sobre Participación de los Pueblos Indígenas originarios y formas de representación, pp. 140-150. La Paz, Fondo Indígena.

Coronit, Fernando (2004). Latin American postcolonial studies and global decolonization. En Pramod K Nayar (Ed.) Postcolonial Studies: An Anthology. John Wiley\&Sons.

Garretón, Manuel Antonio. (2010). La problemática actual de América Latina y las respuestas en juego. En, M. Salazar y A. Osorio (edits.), Democracia y antagonismo en el Chile contemporáneo. perspectivas post-transcicionales. Santiago, Akhilleus.

Gómez Leyton, Juan Carlos (Ed) (2017): Jiménez Cortés, Elizabeth; Johnson Barella, Doris; Escárzaga Nicté, Fabiola; Leiva GuZmán, Andrés;Z egada Claurey, María Teresa y Gibert Galassi, Jorge (2017), Bolivia hoy: ¿Una democracia poscolonial o anticolonial? Seis estudios y una bibliografía seleccionada 1990-2016. Santiago, Ediciones Escaparate.

Zegada, María Teresa; Arce, C.; Canedo, G.; Quispe, A. (2011). Democracia de los márgenes: transformaciones en el campo político boliviano. La Paz, CLACSO, Muela del Diablo. 